\title{
DECISION ANALYSIS FOR BIG DATA PLATFORM SELECTION
}

\author{
Galina Ilieva \\ Faculty of Economics and Social Sciences, \\ University of Plovdiv Paisii Hilendarski, \\ 24, Tzar Asen St., 4000 Plovdiv, Bulgaria \\ Institute of Information and Communication Technologies, \\ Bulgarian Academy of Sciences, \\ Acad. G. Bonchev St., Block 2, 1113 Sofia, Bulgaria, \\ e-mail: galili@uni-plovdiv.bg
}

\begin{abstract}
The accumulation of enormous quantities of structured and unstructured data in the organizations is a prerequisite for the appearance of different IT solutions for data warehousing and fast processing of huge collections of information. The objective of this research is to compare frequently used cloudbased resources for large volumes of data focusing on their specific characteristics. This comparison will be a stepping stone in the creation of a fuzzy multi-criteria system for evaluating cloud platforms for deploying, operating and analysis of big data.

Keywords: multi-criteria decision-making, big data, cloud service evaluation, QoS, fuzzy TOPSIS, fuzzy VIKOR, fuzzy EDAS.
\end{abstract}

\section{INTRODUCTION}

The implementation of big data platforms in business models in modern companies creates new possibilities for product personalization, customer relationships and supply chains integration. In the last few years, big data has been the subject of multitude research studies. Many researchers consider the fundamental concepts, particularities, business value and challenges of massive volumes of data [1-3], while others analyze characteristics of business intelligent systems with big data pertaining to different fields of applications $[4,5]$.

Regardless of great interest in the topic, there is still no strict definition of the term "big data". According to one of the definitions most frequently quoted in literature, "big data" refers to a set of data whose amount exceeds the capabilities of ordinary databases for collection, storage, management and

DOI: 10.7546/EngSci.LVI.19.02.01

(c) Инженерни науки, год. LVI, 2019, № 2

(C) Engineering Sciences, LVI, 2019, No. 2 
analysis of information. The term is indicative of subjectivism in determining the qualifying amount of data [6].

Processing big volumes of data, however, constitutes just a part of the problem. As early as 2001, Laney underlined the significance of the three Vs Volume, Velocity and Variety as a key challenge in electronic commerce data management [7]. The last aspect of the concept is related to the variety of unstructured and semi-structured data, as more and more frequently multimedia content, blogs' records, reviews, comments and unstructured documents are used in practice.

At present, a set of approaches, instruments and methods for processing enormous volumes of structured and non-structured, diversified and continuously growing data is labelled as "big data". Typically, a distributed computing system stands behind applications for big data processing, as operations require a group of powerful computers united in a high-performance computing cluster.

Due to increased volume and variety, companies' data are already difficult to process with classical software systems such as Supply Chain Management (SCM), Manufacturing Execution System (MES) or Enterprise Resource Planning (ERP). Demanding requirements in terms of big volume, velocity, variety and value added resulted in the need of supplementing production systems with cloud platforms for storage and processing of big data collected in organizations for years on end. Big data analytics software, like business intelligence software, analyzes data generated from transaction systems or other company sources and provides assistance in making managerial decisions. Big data analysis systems also generate additional benefits during business processes like sales order acceptance, selection of suppliers, new warehouse location, maintenance, recycling.

\section{RELATED WORK}

Due to the increasing number of technological solutions for storage and fast processing of enormous amounts of data, the selection of a big data platform turns into a serious challenge for a lot of organizations.

Nawaz et al. propose a new methodology which provides a prioritized list of cloud services based on the pattern of changing user preferences. To compare available services, they evaluate Quality of Service (QoS) via a recently invented multi-criteria decision-making method, Best Worst Method [8].

As processing vast data amounts assumes a lot of ambiguities preventing users from making reasonable decisions, it is desirable to deal with fuzzy infor-

(c) Инженерни науки, год. LVI, 2019, № 26 (c) Engineering Sciences, LVI, 2019, No. 2 
mation while selecting appropriate technology in an uncertain environment. Sun et al. build a fuzzy ontology to model relationships between objects in databases for service matching, and present a novel Analytic Hierarchy Process (AHP) approach to calculate semantic similarity between concepts. They also present a multi-criteria decision-making technique that ranks cloud services [9].

Upadhyay addresses a substantial issue in evaluating performance of cloud services and proposes a new evaluation and ranking framework. Firstly, the importance of cloud computing and the significance of Quality of Service (QoS) selection problem is introduced. Then, the framework is provided to illustrate the QoS evaluation approach [10].

Jaiswal and Mishra also rank cloud services based on quantified QoS attributes using Technique for Order of Preference by Similarity to Ideal Solution (TOPSIS) and fuzzy TOPSIS, and comparing them to find out which method is more suitable in different scenarios. A comparative study of AHP and Analytic Network Process (ANP) is also done while extracting the weights of criteria for TOPSIS and fuzzy TOPSIS [11].

According to Sohaib et al., it is important for decision makers to adopt the optimal cloud computing service model, which is a multi-criteria decisionmaking problem. To address this problem, they propose a 2-tuple fuzzy linguistic multi-criteria group decision-making method based on TOPSIS and rely on a Technology-Organization-Environment (TOE) framework to determine a set of appropriate criteria. The resulting analysis indicates that SaaS is the best choice for small and medium-sized e-commerce businesses considering criteria such as complexity, reliability, security and privacy, organization readiness and firm size, while the selection of PaaS or IaaS can be reinforced considering their compatibility and scalability [12].

Krishankumar et al. create a new ranking framework for optimal selection of cloud vendor for an organization. First, the authors define a set of target dimensions for cloud computing from customer point of view, based on expert reviews, international literature reviews and market analysis of cloud providers. This study proposes Intuitionistic Fuzzy Analytic Hierarchy Process (IF-AHP) for effective cloud vendor selection. In previous approaches, IF-AHP was mainly used in determining criteria weights and ranking was performed without consistency check of the decision matrices. This led to unrealistic preference orders. To alleviate this issue, a new ranking framework with IF-AHP is proposed here in order to provide both pair-wise comparison and consistency check for decision matrices [13].

(c) Инженерни науки, год. LVI, 2019, № 27

(C) Engineering Sciences, LVI, 2019, No. 2 
Companies, however, lag behind in adopting platforms for data analysis, as compared to other kinds of business software. On the one hand, this is due to high capital expenses needed for automation, integration and processing data flows from individual software systems, machines, and transportation devices. On the other hand, production organizations evaluate the benefits of data analysis, while recognizing the fact that their lack of success at its introduction constitutes a risk for their operational and financial efficiency. According to Gartner, $60 \%$ of big data projects do not get to a successful finale due to the absence of appropriate IT skills, failure to understand stakeholder requirements and the availability of many legacy systems [14]. Manufacturers' reluctance to introduce data analysis instruments into their activities also stems from here.

An inadequate choice or upgrade of existing company systems with a new technology for big data may result in serious consequences at a later stage, when rectification attempts are rather expensive. Data analysis platforms in production have a lot of advantages such as reliability, scalability, cheap maintenance and low expenditures for development. However, there are also unforeseen risks. For instance, inappropriate technology may exert adverse impact over productivity and real time processing of sensor data. Selecting an inappropriate algorithm for sensor data analysis in a product line may exert negative influence over real time management systems' performance. Therefore, regardless of preceding investigations described above, assessment and comparison of big data platforms continues to be a topical problem. The purpose of this research is to compare frequently used platforms for massive data processing focusing onto their peculiarities. This comparison will be a stepping stone in the creation of a fuzzy multi-criteria system for evaluating cloud platforms for deploying, operating and analysis of big data.

\section{DECISION MAKING ANALYSIS}

The decision-making process depends on a multitude of factors related to an organization's business model and particularities of surrounding environment. In its essence, this is a multi-criteria task [15-20]. Inaccurate, incomplete and fast changing data about alternatives under comparison make precise calculations impossible and the idea of making decisions on the grounds of fuzzy relations and evaluations of alternatives compared in conformity with given criteria is logically easily arrived at [21-27]. Investigations continue seeking new algorithms for decision analysis via more sophisticated forms of classic fuzzy sets [28-31]. We will consider in brief a few algorithms for MCDA with

(c) Инженерни науки, год. LVI, 2019, № 28 (c) Engineering Sciences, LVI, 2019, No. 2 
fuzzy triangular numbers - TOPSIS method, VIseKriterijumska Optimizacija I Kompromisno Resenje (VIKOR) method and Evaluation based on Distance from Average Solution (EDAS) method.

Let a MCDM problem have $n$ alternatives $\left(A_{1}, \ldots, A_{n}\right), m$ decision criteria $\left(C_{1}, \ldots, C_{m}\right)$ and each alternative be assessed according to the given criteria. Decision matrix $X=\left(x_{i j}\right)_{n x m}$ shows all values which are assigned to the alternatives for each criterion. The related weight of each criterion is denoted as $W=\left(w_{1}, \ldots, w_{m}\right)$.

Figure 1 presents the stepwise modified procedure for implementing TOPSIS via fuzzy numbers. After forming an initial decision matrix, the procedure starts by normalizing the decision matrix. This is followed by building the weighted normalized decision matrix in Step 2, determining the optimal and negative-optimal solutions in Step 3. The procedure ends by computing the relative closeness coefficients. The set of alternatives (or candidates) can be ranked according to the descending order of the closeness coefficient [28].

1. Construct the fuzzy decision matrix.

2. Construct the weighted fuzzy decision matrix.

3. Determine the fuzzy optimal and negative-optimal solutions.

4. Calculate the distance to the fuzzy optimal and negative-optimal solutions.

5. Calculate closeness to the fuzzy optimal solution.

6. Rank the alternatives to the closeness to the fuzzy optimal solution.

Fig. 1. The fuzzy TOPSIS flow chart

Figure 2 presents the stepwise procedure for implementing fuzzy VIKOR. After forming an initial decision matrix, the procedure starts by normalizing the decision matrix. This is followed by building the weighted normalized decision matrix in Step 2, and determining the fuzzy optimal and negativeoptimal solutions in Step 3. In step 4 we calculate the separation measures

1. Construct the fuzzy decision matrix.

2. Construct the weighted fuzzy decision matrix.

3. Determine the fuzzy optimal and negative-optimal solutions.

4. Calculate the distances from fuzzy optimal and negative-optimal solutions.

5. Calculate the compromise ranking indices.

6. Rank the alternatives using set of ranking indices.

Fig. 2. The fuzzy VIKOR flow chart

(c) Инженерни науки, год. LVI, 2019, № 2

(C) Engineering Sciences, LVI, 2019, No. 2 
for each alternative. The procedure ends by computing the set of compromise ranking indices. The given alternatives (or candidates) are ranked according to their descending order [29].

In fuzzy EDAS method a pair of matrices is calculated - Positive Distances $(P D)$ from the average and the Negative Distances $(N D)$ from the fuzzy average solution. The evaluation of alternatives is made according to higher appraisal score. The EDAS algorithm is given in Fig. 3 [30, 31].

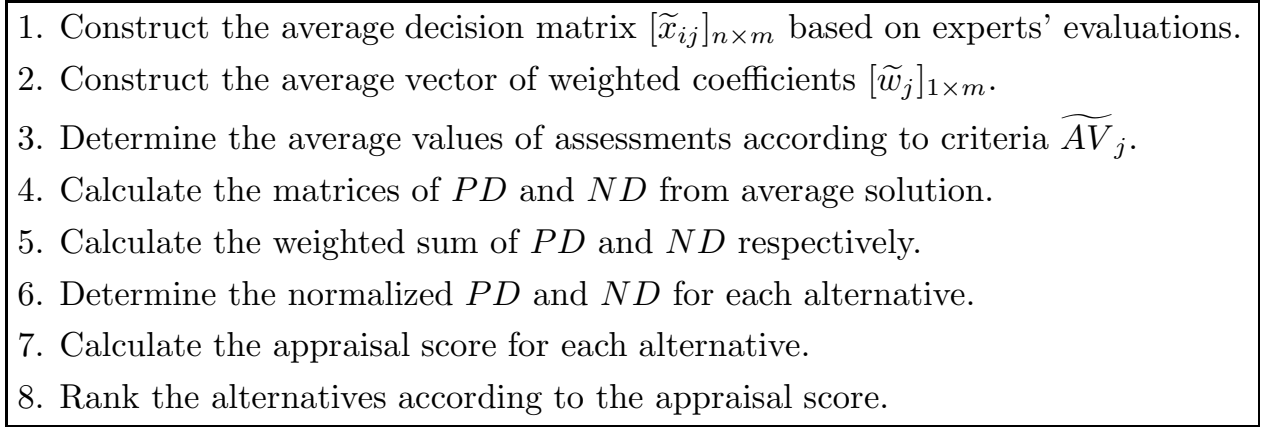

Fig. 3. Flowchart of the fuzzy EDAS algorithm

In the next section, we solve the cloud platform selection task via the three fuzzy multi-criteria algorithms.

\section{PRACTICAL EXAMPLE}

To validate the proposed MCDM methodology, experiments have been conducted for three big data platforms - Platform $1\left(A_{1}\right)$, Platform $2\left(A_{2}\right)$ and Platform $3\left(A_{3}\right)$ and seventeen quality decision criteria, $\left(C_{1}, C_{2}, \ldots, C_{17}\right)$ for two different user requirements. The QoS data is collected from previous evaluation study for three cloud providers - Amazon EC2, Windows Azure and Rackspace [10].

The attributes assessments are shown in Table 1 in order to guarantee the consistency and comparability of obtained results. Criteria weights $\left(w_{C_{i 1}}\right.$, $\left.w_{C_{i 2}}, \ldots, w_{C_{i 17}}\right), i=1 . .2$ associated to respective quality criteria are given in Table 2. Accountability $\left(C_{1}\right)$, CPU Capacity $\left(C_{2}\right)$, Memory Capacity $\left(C_{3}\right)$, Disk Capacity $\left(C_{4}\right)$, Availability $\left(C_{5}\right)$, CPU Service stability $\left(C_{6}\right)$, Memory Service stability $\left(C_{7}\right)$, Free support Serviceability $\left(C_{8}\right)$, Type of Support Serviceability $\left(C_{9}\right)$, and Security $\left(C_{10}\right)$ are benefit criteria. Elasticity Time $\left(C_{11}\right)$, Service stability Upload time $\left(C_{12}\right)$, On-going VM cost $\left(C_{13}\right)$, On-going Data

(c) Инженерни науки, год. LVI, 2019, № $2 \quad 10 \quad$ (c) Engineering Sciences, LVI, 2019, No. 2 
TABLE 1. QoS criteria and values of big data platforms - Platform 1, Platform 2 and Platform 3

\begin{tabular}{|c|c|c|c|c|c|}
\hline \multicolumn{3}{|c|}{ QoS criteria } & Platform 1 & Platform 2 & Platform 3 \\
\hline \multicolumn{3}{|c|}{ Accountability Level: 0-10 } & 4 & 8 & 4 \\
\hline \multirow{4}{*}{ Agility } & \multirow{3}{*}{ Capacity } & $\mathrm{CPU}$ & 9.6 & 12.8 & 8.8 \\
\hline & & Memory & 15 & 14 & 15 \\
\hline & & Disk & 1690 & 2040 & 630 \\
\hline & Elasticity & Time & $80-120$ & $520-780$ & $20-200$ \\
\hline \multirow{6}{*}{ Assurance } & Availability & - & $99.95 \%$ & $99.99 \%$ & $100 \%$ \\
\hline & \multirow{3}{*}{$\begin{array}{l}\text { Service } \\
\text { stability }\end{array}$} & $\begin{array}{l}\text { Upload } \\
\text { time }\end{array}$ & 13.6 & 15 & 21 \\
\hline & & $\mathrm{CPU}$ & 17.9 & 16 & 23 \\
\hline & & Memory & 7 & 12 & 5 \\
\hline & \multirow[b]{2}{*}{ Serviceability } & $\begin{array}{l}\text { Free } \\
\text { support }\end{array}$ & 0 & 1 & 1 \\
\hline & & $\begin{array}{l}\text { Type of } \\
\text { support }\end{array}$ & $\begin{array}{r}24 / 7, \\
\text { Phone, } \\
\text { Urgent } \\
\text { response, } \\
\text { Diagnostic } \\
\text { tools }\end{array}$ & $\begin{array}{r}24 / 7, \\
\text { Phone, } \\
\text { Urgent } \\
\text { response, } \\
\text { Diagnostic } \\
\text { tools }\end{array}$ & $\begin{array}{r}24 / 7, \\
\text { Phone, } \\
\text { Urgent } \\
\text { response, } \\
\text { Diagnostic } \\
\text { tools }\end{array}$ \\
\hline \multirow{3}{*}{ Cost } & \multirow{3}{*}{ On-going cost } & $\mathrm{VM}$ cost & 0.68 & 0.96 & 0.96 \\
\hline & & Data cost & 10 & 10 & 8 \\
\hline & & $\begin{array}{l}\text { Storage } \\
\text { cost }\end{array}$ & 12 & 15 & 15 \\
\hline \multirow[b]{2}{*}{ Performance } & \multirow[b]{2}{*}{$\begin{array}{l}\text { Service } \\
\text { response time }\end{array}$} & Range & $80-120$ & $520-780$ & $20-200$ \\
\hline & & $\begin{array}{l}\text { Average } \\
\text { value }\end{array}$ & 100 & 600 & 30 \\
\hline \multicolumn{3}{|l|}{ Security level } & 4 & 8 & 4 \\
\hline
\end{tabular}

Source: [10]

cost, On-going Storage cost $\left(C_{15}\right)$, Service response time range $\left(C_{16}\right)$, and Service response time Average value $\left(C_{17}\right)$ are cost attribute.

The values in the decision matrix are shown in Table 3 as seven grade linguistic variables. For transforming every linguistic variable into its corresponding symmetric triangular fuzzy number, we apply a correspondence

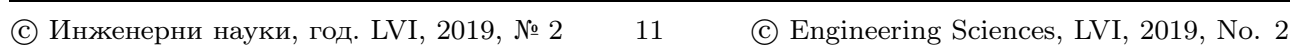


TABLE 2. Consumer requirement weights for the criteria $\left(C_{1}, C_{2}, \ldots, C_{17}\right)$

\begin{tabular}{|l|c|c|c|c|c|c|c|c|c|}
\hline \multirow{2}{*}{$\begin{array}{l}\text { User } \\
\text { require- }\end{array}$} & $w_{C_{1,1}}$ & $w_{C_{1,2}}$ & $w_{C_{1,3}}$ & $w_{C_{1,4}}$ & $w_{C_{1,5}}$ & $w_{C_{1,6}}$ & $w_{C_{1,7}}$ & $w_{C_{1,8}}$ & $w_{C_{1,9}}$ \\
\cline { 2 - 11 } ment 1 & 0.05 & 0.5 & 0.3 & 0.2 & 0.7 & 0.4 & 0.3 & 0.7 & 0.3 \\
\cline { 2 - 11 } & $w_{C_{1,10}}$ & $w_{C_{1,11}}$ & $w_{C_{1,12}}$ & $w_{C_{1,13}}$ & $w_{C_{1,14}}$ & $w_{C_{1,15}}$ & $w_{C_{1,16}}$ & $w_{C_{1,17}}$ & \\
\hline \multirow{2}{*}{$\begin{array}{l}\text { User } \\
\text { require- } \\
\text { ment 2 }\end{array}$} & 0.05 & 0.6 & 0.3 & 0.6 & 0.2 & 0.2 & 0.5 & 0.5 & \\
\cline { 2 - 11 } & $w_{C_{2,1}}$ & $w_{C_{2,2}}$ & $w_{C_{2,3}}$ & $w_{C_{2,4}}$ & $w_{C_{2,5}}$ & $w_{C_{2,6}}$ & $w_{C_{2,7}}$ & $w_{C_{2,8}}$ & $w_{C_{2,9}}$ \\
\cline { 2 - 11 } & $w_{C_{2,10}}$ & $w_{C_{2,11}}$ & $w_{C_{2,12}}$ & $w_{C_{2,13}}$ & $w_{C_{2,14}}$ & $w_{C_{2,15}}$ & $w_{C_{2,16}}$ & $w_{C_{2,17}}$ & \\
\hline
\end{tabular}

Source: $[10]$

TABLE 3. Decision matrix and weights of the criteria

\begin{tabular}{|c|c|c|c|c|c|c|c|c|c|}
\hline Alternatives & $C_{1}$ & $C_{2}$ & $C_{3}$ & $C_{4}$ & $C_{5}$ & $C_{6}$ & $C_{7}$ & $C_{8}$ & $C_{9}$ \\
\hline$A_{1}$ & $\mathrm{VL}$ & $\mathrm{L}$ & $\mathrm{VH}$ & $\mathrm{H}$ & $\mathrm{VL}$ & $\mathrm{ML}$ & $\mathrm{ML}$ & $\mathrm{VL}$ & $\mathrm{VH}$ \\
\hline$A_{2}$ & $\mathrm{VH}$ & $\mathrm{VH}$ & $\mathrm{VL}$ & $\mathrm{VH}$ & $\mathrm{H}$ & $\mathrm{VL}$ & $\mathrm{VH}$ & $\mathrm{VH}$ & $\mathrm{VH}$ \\
\hline$A_{3}$ & $\mathrm{VL}$ & $\mathrm{VL}$ & $\mathrm{VH}$ & $\mathrm{VL}$ & $\mathrm{VH}$ & $\mathrm{VH}$ & $\mathrm{VL}$ & $\mathrm{VH}$ & $\mathrm{VH}$ \\
\hline Alternatives & $\mathrm{C}_{10}$ & $\mathrm{C}_{11}$ & $\mathrm{C}_{12}$ & $\mathrm{C}_{13}$ & $\mathrm{C}_{14}$ & $\mathrm{C}_{15}$ & $\mathrm{C}_{16}$ & $\mathrm{C}_{17}$ & \\
\hline$A_{1}$ & $\mathrm{VL}$ & $\mathrm{VH}$ & $\mathrm{VH}$ & $\mathrm{VH}$ & $\mathrm{VL}$ & $\mathrm{VH}$ & $\mathrm{VH}$ & $\mathrm{H}$ & \\
\hline$A_{2}$ & $\mathrm{VH}$ & $\mathrm{VL}$ & $\mathrm{VL}$ & $\mathrm{VL}$ & $\mathrm{VL}$ & $\mathrm{VL}$ & $\mathrm{VL}$ & $\mathrm{VL}$ & \\
\hline$A_{3}$ & $\mathrm{VL}$ & $\mathrm{VH}$ & $\mathrm{VL}$ & $\mathrm{VL}$ & $\mathrm{VH}$ & $\mathrm{VL}$ & $\mathrm{VH}$ & $\mathrm{VH}$ & \\
& & & & & & & \multicolumn{2}{|c}{}
\end{tabular}

TABLE 4. Linguistic terms and their corresponding triangular fuzzy numbers

\begin{tabular}{|l|l|}
\hline Linguistic term & Triangular FNs \\
\hline Very low (VL) & $(0,0,0.17)$ \\
\hline Low $(\mathrm{L})$ & $(0,0.17,0.33)$ \\
\hline Medium Low (ML) & $(0,0.17,0.33)$ \\
\hline Medium (M) & $(0.33,0.5,0.67)$ \\
\hline Medium High (MH) & $(0.5,0.67,0.83)$ \\
\hline High $(\mathrm{H})$ & $(0.67,0.83,1)$ \\
\hline Very High $(\mathrm{VH})$ & $(0.83,1,1)$ \\
\hline
\end{tabular}

table (Table 4). The membership functions of the linguistic terms are shown in Fig. 4.

In the current work, the big data platform is selected from three cloud providers and two user's requirements. The results of the calculations per-

(c) Инженерни науки, год. LVI, 2019, № $2 \quad 12$ (c) Engineering Sciences, LVI, 2019, No. 2 


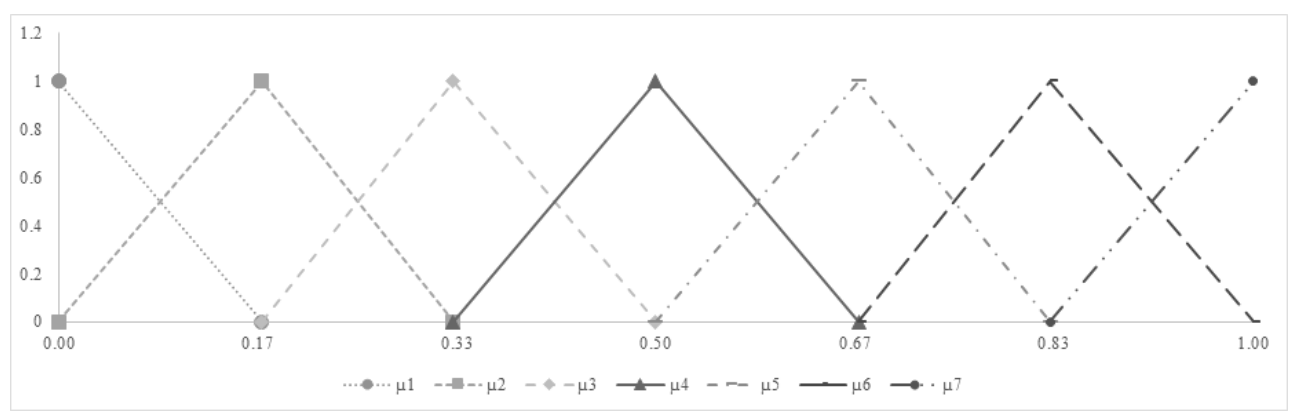

Fig. 4. Membership functions of the linguistic terms

formed via three fuzzy multi criteria decision making methods are shown in Table 5-Table $7^{2}$

TABLE 5. Case study - QoS evaluation and ranking of big data platforms - Platform 1, Platform 2 and Platform 3 by using fuzzy triangular TOPSIS

\begin{tabular}{|l|c|c|c|c|c|}
\hline & & $d_{i}^{*}$ & $d_{i}^{-}$ & $C C_{i}$ & Ranking \\
\hline \multirow{3}{*}{ User requirement 1 } & $A_{1}$ & 0.7229 & 0.5081 & 0.4128 & 2 \\
\cline { 2 - 6 } & $A_{2}$ & 0.7729 & 0.4282 & 0.3565 & 3 \\
\cline { 2 - 6 } & $A_{3}$ & 0.6896 & 0.5537 & 0.4454 & 1 \\
\hline \multirow{3}{*}{ User requirement 2 } & $A_{1}$ & 0.7752 & 0.4030 & 0.3421 & 2 \\
\cline { 2 - 6 } & $A_{2}$ & 0.8171 & 0.3415 & 0.2948 & 3 \\
\cline { 2 - 6 } & $A_{3}$ & 0.7507 & 0.4386 & 0.3688 & 1 \\
\hline
\end{tabular}

TABLE 6. Case study - QoS evaluation and ranking of big data platforms - Platform 1, Platform 2 and Platform 3 by using fuzzy triangular VIKOR

\begin{tabular}{|l|c|c|c|c|c|c|c|}
\hline & & $S_{i}$ & Ranking & $Q_{i}$ & Ranking & $R_{i}$ & Ranking \\
\hline \multirow{3}{*}{ User requirement 1} & $A_{1}$ & 3.5261 & 2 & 0.9852 & 2 & 0.7247 & 2 \\
\cline { 2 - 9 } & $A_{2}$ & 4.5021 & 3 & 0.8 & 3 & 0.5 & 3 \\
\cline { 2 - 8 } & $A_{3}$ & 2.7293 & 1 & 0.8 & 1 & 0 & 1 \\
\hline \multirow{3}{*}{ User requirement 2 } & $A_{1}$ & 0.7752 & 2 & 0.9853 & 2 & 0.7056 & 2 \\
\cline { 2 - 8 } & $A_{2}$ & 0.8171 & 3 & 0.8 & 3 & 0.5 & 3 \\
\cline { 2 - 8 } & $A_{3}$ & 0.7507 & 1 & 0.8 & 1 & 0 & 1 \\
\hline
\end{tabular}

\footnotetext{
${ }^{2}$ Step-by-step calculations for TOPSIS, VIKOR and EDAS methods via triangular fuzzy numbers are available online on web address http://web.uni-plovdiv.bg/galili/ Decision_Analysis_for_Big_Data_Platform_Selection/Web_Appendix.pdf.
}

(c) Инженерни науки, год. LVI, 2019, № 213 (c) Engineering Sciences, LVI, 2019, No. 2 
TABLE 7. Case study - QoS evaluation and ranking of big data platforms - Platform 1, Platform 2 and Platform 3 by using fuzzy triangular EDAS

\begin{tabular}{|l|c|c|c|c|c|}
\hline & & NSP & NSN & Average & Ranking \\
\hline \multirow{3}{*}{ User requirement 1 } & $A_{1}$ & 1 & 0.2912 & 0.6456 & 2 \\
\cline { 2 - 6 } & $A_{2}$ & 0.885 & 0 & 0.4425 & 3 \\
\cline { 2 - 6 } & $A_{3}$ & 0.984 & 0.3409 & 0.6624 & 1 \\
\hline \multirow{3}{*}{ User requirement 2 } & $A_{1}$ & 1 & 0.29982 & 0.6499 & 2 \\
\cline { 2 - 6 } & $A_{2}$ & 0.7101 & 0 & 0.355 & 3 \\
\cline { 2 - 6 } & $A_{3}$ & 0.9794 & 0.3480 & 0.6637 & 1 \\
\hline
\end{tabular}

The proposed methods are able to handle qualitative and quantitative data for big data platform selection based on their QoS attributes. The results show that for user requirement 1 the three platforms are ranked as $A_{3} \succ$ $A_{1} \succ A_{2}$ via three algorithms. For user requirement 2, the three alternatives result into the same ranking: $A_{3} \succ A_{1} \succ A_{2}$. The produced results are consistent with the results mentioned by Upadhyay [10]. The advantages of the proposed solution are in fact that it is effective, computationally simple and easy to use. The proposed fuzzy algorithms combination could be useful to the different stakeholders in big data evaluation, for example, architects, analysts, developers, designers, testers, consultants and managers in big data providers.

\section{CONCLUSION}

Big data opens new possibilities, yet it also poses serious challenges to businesses regarding accessibility, processing velocity and company information security. Big data analysis software finds numerous applications in health care, insurance, intelligent factories, and social network among others. The benefits of employing algorithms for analysis of enormous data amounts are multilateral, as they facilitate data sharing, improve company key performance indicators, enhance decision-making process and improve company competitiveness. The proposed algorithms are computationally economical, flexible and manageable for evaluating and ranking big data platforms. Via an illustrative case study, the validity and applicability of proposed methods was demonstrated. In future work, the assessment mechanism will be extended to cope with uncertainty in QoS requirements for big data by using more sophisticated fuzzy numbers.

(c) Инженерни науки, год. LVI, 2019, № 2 14 (c) Engineering Sciences, LVI, 2019, No. 2 


\section{ACKNOWLEDGEMENTS}

The research is supported by the NPD - Plovdiv University under grant No. FP19-FESS-014 "Contemporary tools and approaches for economic and business analysis" and European Regional Development Fund under grant BG05M2OP001-1.002-0002-C02 "Digitization of Economy in Big Data Environment".

\section{REFERENCES}

[1] S. Kaisler, F. Armour, A. Espinosa And W. Money, Big data: issues and challenges moving forward, in: Proceedings of 46th Hawaii International Conference on System Sciences, 2013, pp. 995-1004, ISBN 978-1-4673-5933-7, doi:10.1109/HICSS.2013.645.

[2] M. Chen, S. Mao and Y. Liu, Big data: a survey, Mobile Networks and Applications (2014) 19 (2) 171-209, ISSN 1383-469X, doi: 10.1007/s11036-013-0489-0.

[3] F. Iafrate, A journey from big data to smart data, Digital Enterprise Design $\mathcal{E}^{3}$ Management, Advances in Intelligent Systems and Computing (2014) 261 25-33, ISBN 978-3-319-04312-8, doi: 10.1007/978-3-319-04313-5_3.

[4] H. Chen, R. Chiang and V. Storey, Business intelligence and analytics: from big data to big impact, MIS Quarterly: Management Information Systems (2012) 36 (4) 1165-1188, ISSN 0276-7783.

[5] C. Chen And C.-Y. Zhang, Data-intensive applications, challenges, techniques and technologies: a survey on big data, Information Sciences (2014) 275 314-347, ISSN 0020-0255, doi:10.1016/j.ins.2014.01.015.

[6] J. Manyika, M. Chui, B. Brown, J. Bughin, R. Dobbs, C. ROXBURGH AND A. BYERS, Big data: the next frontier for innovation, competition, and productivity, McKinsey Global Institute (2011), https://bigdatawg.nist.gov/pdf/MGI_big_data_full_report.pdf, 31.05.2019

[7] D. LANEY, 3D data management: controlling data volume, velocity and variety, Appl. Delivery Strategies Meta Group (949) (2001), https://blogs.gartner.com/doug-laney/files/2012/01/ad949-3D-DataManagement-Controlling-Data-Volume-Velocity-and-Variety.pdf, 31.05.2019

[8] F. Nawaz, M. R. Asadabadi, N. K. Janjua, O. K. Hussain, E. Chang AND M. SABERI, An MCDM method for cloud service selection using a Markov chain and the best-worst method, Knowledge-Based Systems (2018) 159120 131, ISSN 0950-7051, doi: 10.1016/j.knosys.2018.06.010

[9] L. Sun, J. Ma, Y. Zhang, H. Dong and F. K. Hussain, Cloud-FuSeR: Fuzzy ontology and MCDM based cloud service selection, Future Generation Computer Systems (2016) 57 42-55, ISSN 0167-739X, doi:10.1016/j.future.2015.11.025.

(c) Инженерни науки, год. LVI, 2019, № 2 
[10] N. Upadhyay, Managing Cloud Service Evaluation and Selection, Procedia Computer Science (2017) 122 1061-1068, ISSN 1877-0509, doi:10.1016/j.procs.2017.11.474.

[11] A. JAISWAL AND R. B. Mishra, Cloud service selection using TOPSIS and fuzzy TOPSIS with AHP and ANP, in: ACM International Conference Proceeding Series, 2017, pp. 136-142, ISBN 978-1-4503-4828-7, doi: 10.1145/3036290.3036312

[12] O. Sohaib, M. Naderpour, W. Hussain and L. Martinez, Cloud computing model selection for e-commerce enterprises using a new 2-tuple fuzzy linguistic decision-making method, Computers and Industrial Engineering (2019) 132 47-58, ISSN 0360-8352, doi: 10.1016/j.cie.2019.04.020

[13] R. Krishankumar, S. R. Arvinda, A. Amrutha, J. Premaladha AND K. S. RAVICHANDRAN, A decision making framework under intuitionistic fuzzy environment for solving cloud vendor selection problem, in: International Conference on Networks and Advances in Computational Technologies, NetACT 2017, 8076756, pp. 140-144, ISBN 978-1-5090-6591-2, doi:10.1109/NETACT.2017.8076756

[14] L. GoasdufF, Getting started with advanced analytics is as much about changing mindset and culture as it is about tools and skills, https://www.gartner.com/smarterwithgartner/taking-a-first-step-to-advancedanalytics/ (2015) 31.05.2019

[15] V. Peneva And I. Popchev, Fuzzy multi-criteria decision making algorithms, Compt. Rend. Acad. Bulg. Sci. (2010) 63 (7) 979-992, ISSN 1310-1331.

[16] G. ILIEva, Decision making methods in agent based modeling, in: Proceedings of the Workshop on Applications of Software Agents, 2011, pp. 8-17, ISBN 97886-7031-188-6, doi: 10.13140/RG.2.1.4792.2724.

[17] G. Illeva, A fuzzy approach for bidding strategy selection, Cybernetics and Information Technologies (2012) 12 (1) 61-69, ISSN: 1311-9702.

[18] G. Ilieva And A. Dimitrov, Inter-criteria comparison of Bulgarian construction companies using fuzzy relations, Int. Journal of Engineering Science and Innovative Technologies (2015) 4 (2) 290-299, ISSN: 2319-5967.

[19] I. RADEVA, Multicriteria fuzzy sets application in economic clustering problems, Cybernetics and Information Technologies (2017) 17 (3) 29-46, ISSN 1311-9702, doi:10.1515/cait-2017-0028.

[20] H. GARG, Analysis of an industrial system under uncertain environment by using different types of fuzzy numbers, Int. J. Systems Assurance Engineering and Management (2018) 9 (2) 525-538, ISSN 0975-6809, doi: 10.1007/s13198018-0699-8

[21] I. Popchev And V. Peneva, An algorithm for comparison of fuzzy sets, Fuzzy sets and systems (1993) 60 (1) 59-65, ISSN 0165-0114.

[22] V. Peneva And I. Popchev, Fuzzy ordering on the basis of multicriteria aggregation, Cybernetics and Systems (1998) 29 (6) 613-623, ISSN 0196-9722.

(c) Инженерни науки, год. LVI, 2019, № 2 16 (c) Engineering Sciences, LVI, 2019, No. 2 
[23] V. Peneva And I. Popchev, Fuzzy logic operators in decision-making, Cybernetics and Systems (1999) 30 (6) 725-745, ISSN 0196-9722.

[24] V. Peneva And I. Popchev, Aggregation on fuzzy numbers in a decision making situation, Cybernetics and Systems (2001) 32 (8) 871-885, ISSN 0196-9722.

[25] V. Peneva and I. Popchev, Fuzzy criteria importance with weighting functions, Comptes Rend. Acad. Bulg. Sci. (2008) 61 (3) 293-300, ISSN 1310-1331.

[26] V. Peneva And I. Popchev, Fuzzy criteria importance depending on membership degrees of fuzzy relations, Comptes Rend. Acad. Bulg. Sci. (2008) 61 (5) 579-584, ISSN 1310-1331.

[27] V. Peneva And I. Popchev, Models for decision making by fuzzy relations and fuzzy numbers for criteria evaluations, Comptes Rend. Acad. Bulg. Sci. (2009) 62 (10) 1217-1222, ISSN 1310-1331.

[28] G. IlIEva, TOPSIS modification with interval type-2 fuzzy numbers, Cybernetics and Information Technologies (2016) 16 (2) 60-68, ISSN 1311-9702.

[29] G. ILIEva, Group decision analysis with interval type-2 fuzzy numbers, Cybernetics and Information Technologies (2017) 17 (1) 31-44, ISSN 1311-9702, doi: 10.1515/cait-2017-0003.

[30] G. ILIEvA, Group decision analysis algorithms with EDAS for interval fuzzy sets, Cybernetics and Information Technologies (2018) 18 (2) 51-64, ISSN 1311-9702, doi: 10.2478/cait-2018-0027.

[31] G. Ilieva, T. Yankova and S. Klisarova-Belcheva, Decision analysis with classic and fuzzy EDAS modifications, Computational and Applied Mathematics (2018) 37 (5) 5650-5680, ISSN 2238-3603, doi: 10.1007/s40314-018-0652-0.

\title{
МНОГОКРИТЕРИАЛЕН АНАЛИЗ ЗА ИЗБОР НА ПЛАТФОРМА ЗА ГОЛЕМИ ДАННИ
}

\author{
ГАЛИНА ИЛИЕВА \\ Факултет „Икономически и сочиални науки“, \\ Пловдивски университет "Паисий Хилендарски", \\ ул. „Цар Асен“"№ 24, 4000 Пловдив, Бглгария,
}

Институт по информационни и комуникационни технологии,

Българска академия на науките, ул. „Акад. Георги Бончев“, Блок 2, 1113 София, Бглгария, e-mail: galili@uni-plovdiv.bg

Резюме. Натрупването на огромни количества неструктурирани и структурирани данни в организациите е предпоставка за появата на нови високотехнологични решения за съхранение и бърза обработка на огромни масиви информация. Целта на изследването е да се сравнят някои от най-

(c) Инженерни науки, год. LVI, 2019, № 2 
разпространените облачни платформи за обработка на масивни данни с акцент върху техните характерни особености. Сравнението ще послужи за създаване на размита критериална система за избор на софтуерни средства и среди за съхранение и анализ на големи данни.

Ключови думи: многокритериално вземане на решения, големи данни, сравнение на облачни услуги, качество на обслужване, размит TOPSIS, размит VIKOR, размит EDAS.

Received April 22, 2019

(c) Инженерни науки, год. LVI, 2019, № 2 